\title{
BMJ
}

\section{Effectiveness of a multifaceted podiatry intervention to prevent falls in community dwelling older people with disabling foot pain: randomised controlled trial}

\author{
Martin J Spink, PhD candidate, ${ }^{1,2}$ Hylton B Menz, professor, ${ }^{1}$ Mohammad R Fotoohabadi, research officer, ${ }^{1}$ Elin \\ Wee, research officer, ${ }^{1}$ Karl B Landorf, senior lecturer ${ }^{1,2}$ Keith D Hill, professor of allied health, ${ }^{1,3,4}$ Stephen R \\ Lord, senior principal research fellow ${ }^{5,6}$
}

$\overline{{ }^{1} \text { Musculoskeletal Research Centre, }}$ Faculty of Health Sciences, La Trobe University, Bundoora Victoria, Australia

${ }^{2}$ Department of Podiatry, Faculty of Health Sciences, La Trobe University, Bundoora, Victoria, Australia

${ }^{3}$ Division of Allied Health, Northern Health, Epping, Victoria, Australia

${ }^{4}$ Preventive and Public Health Division, National Ageing Research Institute, Parkville, Victoria,

Australia

${ }^{5}$ School of Public Health and Community Medicine, University of New South Wales (UNSW), Sydney, NSW, Australia

${ }^{6}$ Neuroscience Research Australia, Randwick, Sydney, NSW, Australia Correspondence to: H B Menz h.menz@latrobe.edu.au

Cite this as: $B M J$ J 2011;342:d3411 doi:10.1136/bmj.d3411

\section{ABSTRACT}

Objective To determine the effectiveness of a multifaceted podiatry intervention in preventing falls in community dwelling older people with disabling foot pain.

Design Parallel group randomised controlled trial.

Setting University health sciences clinic in Melbourne, Australia.

Participants 305 community dwelling men and women (mean age 74 (SD 6) years) with disabling foot pain and an increased risk of falling. 153 were allocated to a multifaceted podiatry intervention and 152 to routine podiatry care, with 12 months' follow-up.

Interventions Multifaceted podiatry intervention consisting of foot orthoses, advice on footwear, subsidy for footwear ( $\$ A 100$ voucher; $£ 65 ; € 74$ ), a home based programme of foot and ankle exercises, a falls prevention education booklet, and routine podiatry care for 12 months. The control group received routine podiatry care for 12 months.

Main outcome measures Proportion of fallers and multiple fallers, falling rate, and injuries resulting from falls during follow-up.

Results Overall, 264 falls occurred during the study. 296 participants returned all 12 calendars: 147 (96\%) in the intervention group and 149 (98\%) in the control group. Adherence was good, with $52 \%$ of the participants completing $75 \%$ or more of the requested three exercise sessions weekly, and $55 \%$ of those issued orthoses reporting wearing them most of the time. Participants in the intervention group $(n=153)$ experienced $36 \%$ fewer falls than participants in the control group (incidence rate ratio $0.64,95 \%$ confidence interval 0.45 to $0.91, P=0.01$ ). The proportion of fallers and multiple fallers did not differ significantly between the groups (relative risk $0.85,0.66$ to $1.08, P=0.19$ and $0.63,0.38$ to $1.04, P=0.07$ ). One fracture occurred in the intervention group and seven in the control group $(0.14,0.02$ to $1.15, \mathrm{P}=0.07)$. Significant improvements in the intervention group compared with the control group were found for the domains of strength (ankle eversion), range of motion (ankle dorsiflexion and inversion/eversion), and balance (postural sway on the floor when barefoot and maximum balance range wearing shoes).

Conclusions A multifaceted podiatry intervention reduced the rate of falls in community dwelling older people with disabling foot pain. The components of the intervention are inexpensive and relatively simple to implement, suggesting that the programme could be incorporated into routine podiatry practice or multidisciplinary falls prevention clinics.

Trial registration Australian New Zealand Clinical Trials Registry ACTRN12608000065392.

\section{INTRODUCTION}

Falls in older people are a major public health problem, with 1 in 3 people aged 65 and over falling each year. ${ }^{12}$ It is well recognised that falls result from the interaction between environmental hazards and physiological risk factors, such as impaired vision, muscle weakness, and slow reaction time. ${ }^{1-4}$ More recently, foot problems, which affect 1 in 3 older people $^{5-7}$ and are a common reason for consultation in primary care, ${ }^{8}$ have been associated with falls. Specifically, foot pain, reduced range of motion, toe weakness, and toe deformity have each been shown to be independent risk factors for falling. ${ }^{910}$ In addition, footwear related risk factors for falls include walking barefoot, walking in socks alone or wearing shoes with inadequate fixation (that is, no laces, straps, or buckles), increased heel height, and reduced contact area of sole. ${ }^{11-14}$

Given the emerging evidence that foot problems and inappropriate footwear increase the risk of falls, several guidelines for falls prevention recommend that older people have their feet and footwear examined by a podiatrist. ${ }^{15-18}$ These guidelines do not, however, specify the assessment or intervention activities to be undertaken, and few randomised controlled trials have been carried out to inform clinical practice. Three multifactorial intervention studies have included assessment of participants' feet and footwear as part of the protocol, with referral to a podiatrist when appropriate. ${ }^{19-21}$ However, the criteria for referral to a 
podiatrist were not described nor was there any analysis of the effectiveness or benefit of such referrals. Only one trial has been undertaken in relation to footwear, which specifically focused on a modification to reduce slipping on icy surfaces. ${ }^{22}$

To deal with this gap in the literature and to determine whether podiatry has a role in falls prevention, we carried out a randomised controlled trial to determine the effectiveness of a novel, multifaceted podiatry intervention addressing foot and footwear risk factors in reducing the rate of falls in older community dwelling people with disabling foot pain.

\section{METHODS}

Between July 2008 and September 2009 we recruited participants by post using a database of people who were accessing podiatry services at the La Trobe University Health Sciences Clinic, Bundoora, Victoria, Australia, and by advertisements in local newspapers and on the radio. Participants were eligible if they were community dwelling, were aged 65 years or over, were cognitively intact (defined as a score of $\geq 7$ on the short portable mental status questionnaire) ${ }^{23}$ reported disabling foot pain (defined as foot pain lasting for at least a day within the last month and a positive response of "some days" or "most/every days" to at least one item on the Manchester foot pain and disability index), ${ }^{24}$ and had an increased risk of falling (defined as either a history of a fall in the previous 12 months, a score of $>1$ on the physiological profile assessment tool, ${ }^{3}$ or performance on the alternate stepping test of $>10$ seconds). ${ }^{25}$ Exclusion criteria included neurodegenerative disorders, leg amputation, inability to walk household distances $(10 \mathrm{~m}$ ) without the use of a walking aid, limited English language skills, and leg surgery three months before the initial assessment or planned leg surgery within a period of three months of the planned initial assessment.

\section{Trial design}

We carried out a parallel group randomised controlled trial with 12 months' follow-up. An a priori sample size calculation, based on a falling rate of $60 \%$ in the control group, a $30 \%$ reduction in the proportion of fallers in the intervention group, a 15\% dropout rate, $80 \%$ power, and a significance level of 5\%, indicated that we needed 286 participants (143 per group). Participants were initially screened by phone for eligibility then assessed at baseline and at six months after baseline by an assessor blind to group allocation. Two assessors were available for the assessments and were allocated to participants based on their availability. Each participant was tested by the same assessor at both the baseline and six month follow-up appointments. Both assessors (MRF and EW) were physiotherapists. The baseline assessment was carried out after we had obtained written informed consent. Group allocation (randomisation) was then undertaken and the intervention was administered to those in the intervention group by MJS, a podiatrist. This occurred during a single session at the La Trobe
University Health Sciences Clinic. Participants were then provided with a falls calendar to record any falls that occurred in the 12 months after the baseline assessment. Full details of the inclusion criteria and methods are reported in the trial protocol paper. ${ }^{26}$

\section{Randomisation}

Participants were randomly allocated to either the control group or the multifaceted podiatry intervention group. One investigator (MJS, who administered the intervention) used an interactive voice response telephone service provided by the National Health and Medical Research Council Clinical Trials Centre at the University of Sydney to carry out permuted block randomisation with mixed block lengths of four and six participants.

\section{Interventions}

Both the control group and the intervention group were asked to continue with the podiatry treatment they were currently receiving, and all were offered free podiatry treatment at the La Trobe University Health Sciences Clinic for the 12 months of the study. The intervention group was also provided with a multifaceted intervention package consisting of foot orthoses, advice and provision of footwear, a home based foot and ankle exercise programme, and education in falls prevention.

Foot orthoses - we issued prefabricated, full length, dual density orthoses made from a thermoformable cross linked closed cell polyethylene foam with a firm density base and a soft density top cover (Formthotics; Foot Science International, Christchurch, New Zealand) to each participant who was not currently wearing customised or prefabricated orthoses. Consistent with the manufacturer's instructions, the orthoses were heat moulded to each participant's foot shape. The orthoses were then appropriately customised using $3 \mathrm{~mm}$ thick Poron (Rogers, Rogers, CT), a urethane foam, to redistribute pressure away from plantar lesions, such as calluses, that were identified on the participant's forefoot.

Footwear advice and provision - we used a validated footwear assessment form to assess participants' outdoor footwear. ${ }^{27}$ Participants with inappropriate footwear (defined as a heel height $>4.5 \mathrm{~cm}$, or any two of no fixation, no heel counter, a heel counter that could be compressed greater than 45 degrees, a fully worn or smooth sole, or a shoe heel width narrower than the participant's heel by at least $20 \%$ ) were counselled on the specific identified hazardous features of the footwear and were provided with a handout on what constitutes a safe shoe. They were provided with the contact details of an extra depth and medical grade footwear retailer and asked to purchase a more appropriate pair of shoes. The purchase of footwear was subsidised by the provision of a voucher $(\$ A 100 ; £ 65$; $€ 74)$.

Home based foot and ankle exercise programme - participants were asked to perform a standardised 30 minute home based exercise programme three times a week for six months, aimed at stretching and strengthening 
the muscles of the foot and ankle (see web extra on bmj.com). All participants were prescribed the same exercise programme and were instructed to increase the number of repetitions or resistance at a self paced rate based on their ability to perform the exercise with no pain during the movement and no muscle soreness the next day. Participants were provided with a daily exercise diary to document their adherence to the programme and were instructed to return these each month in pre-paid envelopes. MJS telephoned the participants at 1, 4, 12, and 20 weeks to answer any queries and to promote adherence to the programme.

Falls prevention education - we provided each participant with a booklet produced by the Australian Commonwealth Department of Health and Ageing. ${ }^{16}$ This booklet provides a general overview of risk factors for falls and outlines strategies to prevent falls. We also used diagrams and headings in the booklet to explain to each participant their risk of falls and to assist in discussing what participants could do to minimise their risk of falling.

\section{Outcomes}

The primary outcome measures were the proportion of fallers, the proportion of multiple fallers (those who fell on two or more occasions), and the falling rate (the number of falls per participant) in the 12 months after the baseline assessment. Falls were defined as "an unexpected event in which the participant comes to rest on the ground, floor, or lower level." ${ }^{28} \mathrm{We}$ collected data on falls using monthly falls calendars (returned in pre-paid envelopes) with follow-up telephone calls as required.

Assessed for eligibility $(n=847)$

\begin{tabular}{|c|c|}
\hline & $\begin{array}{l}\text { Excluded }(n=542) \text { : } \\
\text { No foot pain }(n=213) \\
\text { Declined }(n=195) \\
\rightarrow \text { Low falls risk }(n=78) \\
\text { Degenerative neurological condition }(n=23) \\
\text { Use of walking aid }(n=18) \\
\text { Insufficient English }(n=15)\end{array}$ \\
\hline \multicolumn{2}{|c|}{ Randomised $(n=305)$} \\
\hline$\downarrow$ & $\downarrow$ \\
\hline $\begin{array}{l}\text { Allocated to intervention group }(n=153) \\
\text { Received allocated intervention }(n=153)\end{array}$ & $\begin{array}{l}\text { Allocated to control group }(n=152) \\
\text { Received allocated intervention }(n=152)\end{array}$ \\
\hline$\downarrow$ & $\downarrow$ \\
\hline $\begin{array}{l}\text { Attended } 6 \text { month assessment }(n=134) \\
\text { Did not attend }(n=19) \text { : } \\
\text { No reason given }(n=5) \\
\text { Illness or injury }(n=13) \\
\text { Lack of time }(n=1)\end{array}$ & $\begin{array}{l}\text { Attended } 6 \text { month assessment }(n=143) \\
\text { Did not attend }(n=9): \\
\text { No reason given }(n=4) \\
\text { Illness or injury }(n=3) \\
\text { Lack of time }(n=2)\end{array}$ \\
\hline$\downarrow$ & $\downarrow$ \\
\hline $\begin{array}{l}\text { Completed } 12 \text { month follow-up }(n=147) \\
\text { Did not complete }(n=6) \text { : } \\
\text { No reason given }(n=3) \\
\text { IIIness or injury }(n=3)\end{array}$ & $\begin{array}{l}\text { Completed } 12 \text { month follow-up }(n=149) \\
\text { Did not complete }(n=3) \text { : } \\
\text { No reason given }(n=2) \\
\text { Died }(n=1)\end{array}$ \\
\hline$\downarrow$ & $\downarrow$ \\
\hline Analysed $(n=153)$ & Analysed $(n=152)$ \\
\hline
\end{tabular}

Flow of participants through study
Secondary outcome measures recorded at baseline and at the six months' follow-up assessment are described in detail in the protocol paper. ${ }^{26}$ These included clinical tests of foot and ankle strength and range of motion, balance, and functional ability; the total physiological profile assessment falls risk score ${ }^{3}$; pain and function subscales of the Manchester foot pain and disability index ${ }^{29}$; the short falls efficacy scale international ${ }^{30}$; and the mental and physical component summary scores of the short form health survey. ${ }^{31}$ The secondary outcomes were assessed at six months, as we considered this period sufficient for all of the interventions to be implemented and for any effects of the exercise programme to be apparent.

\section{Statistical analysis}

All analyses were carried out using the intention to treat principle. We analysed the number of falls per participant by using negative binomial regression to estimate the difference in falls rate between the groups. This approach takes into account all falls and adjusts for varying duration of follow-up. ${ }^{32}$ Using relative risks we compared the proportion of fallers and multiple fallers in each group. We compared the continuously scored secondary outcome measures using the linear regression approach to analysis of covariance, with baseline scores and intervention group entered as independent variables. ${ }^{33}$ Multiple imputation was used to replace missing data for the secondary measures at the six months' follow-up, using five iterations, with age, baseline scores, and group allocation as predictors. ${ }^{34} 35$ Retrospective multiple testing using the Hochberg procedure ${ }^{36}$ was done on the secondary outcome measures, which were divided into eight domains of strength, range of motion, balance, functional ability, falls risk, foot pain and disability, fear of falling, and health related quality of life. Statistical analysis was undertaken using SPSS and Stata statistical software.

\section{RESULTS}

The figure shows the flow of participants through the study. The sample consisted of 305 participants (94 men and 211 women) aged 65 to 93 years, mean age 73.9 (SD 5.9) years. The participants in the two groups had similar baseline characteristics (table 1). The mean duration of foot pain was 6.9 years and the regions most commonly affected were the toes (69\%), forefoot (62\%), mid-foot (48\%), and heel (46\%). During analysis it was identified that one participant who should have been excluded from the study (owing to Parkinson's disease) was inadvertently included and allocated to the control group. To satisfy the intention to treat principle, ${ }^{37}$ data for this participant were included in the analyses (this participant did not report any falls during the trial period).

\section{Intervention adherence and participant retention}

Participation in the exercise intervention as measured by the proportion of self reported completed exercise sessions was $66 \%$, with $52 \%$ of the participants completing $75 \%$ or more of the requested three exercise 
Table 1|Baseline characteristics of participants in intervention (multifaceted podiatry programme) and control (routine podiatry care) groups. Values are numbers (percentages) unless stated otherwise

\begin{tabular}{|c|c|c|}
\hline Characteristics & $\begin{array}{l}\text { Podiatry intervention group } \\
\qquad(\mathrm{n}=153)\end{array}$ & $\begin{array}{l}\text { Control group } \\
(n=152)\end{array}$ \\
\hline Mean (SD) age (years) & $74.2(6.0)$ & $73.6(5.7)$ \\
\hline Women & $106(69)$ & $105(69)$ \\
\hline Living alone & $50(33)$ & $53(35)$ \\
\hline Mean (SD) body mass index & $29.4(5.0)$ & $29.7(5.4)$ \\
\hline \multicolumn{3}{|l|}{ Medical conditions: } \\
\hline Diabetes & $23(15)$ & $31(20)$ \\
\hline Stroke & $10(7)$ & $12(8)$ \\
\hline Heart disease & $34(22)$ & $31(21)$ \\
\hline Osteoarthritis & $106(69)$ & $90(59)$ \\
\hline Rheumatoid arthritis & $12(8)$ & $19(13)$ \\
\hline$\geq 4$ drugs & $91(60)$ & $88(58)$ \\
\hline Fallen in past 12 months & $82(57)$ & $83(55)$ \\
\hline$\geq 2$ falls in previous year & $48(32)$ & $45(30)$ \\
\hline \multicolumn{3}{|l|}{ Physical activity: } \\
\hline Mean (SD) incidental activity (hrs/week) & $33.9(15.2)$ & $36.0(13.2)$ \\
\hline Mean (SD) planned activity (hrs/week) & $3.3(3.5)$ & $3.9(4.3)$ \\
\hline Mean (SD) duration of foot pain (years) & $6.1(7.5)$ & $7.7(8.1)$ \\
\hline \multicolumn{3}{|l|}{ Location of foot pain: } \\
\hline Heel & $80(52.6)$ & $61(39.9)$ \\
\hline Arch & $80(52.6)$ & $67(43.8)$ \\
\hline Forefoot & $92(60.5)$ & $97(63.4)$ \\
\hline Toes & 102 (67.1) & 109 (71.2) \\
\hline
\end{tabular}

sessions per week. At baseline, 50 participants (33\%) in the intervention group and $46(30 \%)$ in the control group were using foot orthoses. Of the 103 participants $(67 \%)$ in the intervention group who were issued with foot orthoses at baseline, the following adherence rates were reported at the six months' follow-up: 57 (55\%) wore the orthoses most of the time, $14(14 \%)$ some of the time, $8(8 \%)$ a little of the time, $8(8 \%)$ none of the time, and $16(15 \%)$ were lost to follow-up.

Inappropriate footwear was identified at the baseline assessment in 41 participants $(27 \%)$ in the intervention group and $46(31 \%)$ in the control group. At the six months' follow-up, of the 41 participants in the intervention group who were issued with footwear vouchers and advice, $15(37 \%)$ reported wearing the new footwear most of the time, $7(17 \%)$ some of the time, 3 $(7 \%)$ a little of the time, $1(3 \%)$ none of the time, 12 $(29 \%)$ did not purchase new footwear, and $3(7 \%)$ were lost to follow-up. The mean number of visits to a podiatrist during the 12 month trial period differed significantly between the intervention and control groups: 4.4 (SD 3.0) v 5.2 (SD 3.0), $\mathrm{P}=0.02$.

At the six month follow-up, 28 participants failed to attend (19 from the intervention group and nine from the control group), giving completion rates of $86 \%$ and $94 \%$, respectively, although some of these continued to provide falls calendars. At the end of the 12 month period, nine participants had withdrawn from the trial (six from the intervention group and three from the control group), giving completion rates of $96 \%$ and $98 \%$, respectively. The figure shows the reasons given for non-completion. One death occurred during the trial, which was unrelated to the intervention and was not falls related. None of the participants reported any adverse events during the trial.

\section{Primary outcomes}

All 305 participants completed one or more falls calendars and 296 returned all 12 calendars: 147 (96\%) in the intervention group and 149 (98\%) in the control group. The mean number of days of follow-up for the primary outcome measures was similar between the intervention and control groups: 357.0 (SD 43.4) $v 361.5$ (30.2). In total, 264 falls occurred during the study, with the intervention group recording 103 and the control group 161. Table 2 shows the rate of falls and the proportion of fallers and multiple fallers in each group over the 12 month period. The mean number of falls per person per year was 1.06 for the control group (range $0-15$ ) and 0.67 for the intervention group (range 0-6). This corresponds to a 36\% reduction in the falls rate during the trial for the intervention group compared with the control group (incidence rate ratio $0.64,95 \%$ confidence interval 0.45 to 0.91 , $\mathrm{P}=0.01)$. The proportion of fallers did not differ significantly between the groups (relative risk $0.85,95 \%$ confidence interval 0.66 to $1.08, \mathrm{P}=0.19$ ) or multiple fallers (0.63, 0.38 to $1.04, \mathrm{P}=0.07)$.

The median number of days to the first fall during follow-up was 85 in the intervention group and 64 in the control group. In total, eight participants had falls that resulted in fractures, with the intervention group accounting for one of these and the control group accounting for the other seven $(0.14,0.02$ to 1.15 , Fisher's exact test, $\mathrm{P}=0.07)$. Five participants in each group were admitted to hospital after a fall. A further seven (two in the intervention group and five in the control group) presented to the emergency department after a fall, and another 24 (13 in the intervention group and 11 in the control group) consulted their general practitioner after a fall.

\section{Secondary outcomes}

Six month follow-up data for the secondary outcome measures were available for $91 \%$ of the participants (87\% of the intervention group and $94 \%$ of the control group). The mean time between baseline and six month follow-up assessments was similar between the intervention and control groups: 184.1 (SD 13.6) $v$ 184.3 (13.4) days. Missing data were considered not to be missing completely at random (Little's test $\left.\chi^{2}=180.8, \mathrm{P}<0.001\right)$ and were therefore imputed, with age, baseline scores, and group allocation as predictors. Table 3 shows baseline and six month scores for the secondary outcome measures in the domains of strength, range of motion, balance, functional ability, risk of falls, foot pain and disability, fear of falling, and health related quality of life. Significant improvements in the intervention group compared with the control group were found for the domains of strength (ankle eversion), range of motion (ankle dorsiflexion and inversion/eversion), and balance (postural sway on 
Table 2 Falls rate and proportions of fallers and multiple fallers by treatment group over 12 month trial period. Values are numbers (percentages) unless stated otherwise

\begin{tabular}{lcccc} 
Outcome measure & $\begin{array}{c}\text { Podiatry intervention } \\
\text { group }(\mathrm{n}=153)\end{array}$ & $\begin{array}{c}\text { Control group } \\
(\mathrm{n}=152)\end{array}$ & $\begin{array}{c}\text { Falls risk ratio } \\
(95 \% \mathrm{Cl})\end{array}$ & Pvalue \\
\hline Mean (range) falls per participant & $0.67(0-6)$ & $1.06(0-15)$ & $0.64(0.45 \text { to } 0.91)^{*}$ & 0.01 \\
\hline$\geq 1$ falls & $64(42)$ & $75(49)$ & $0.85(0.66$ to 1.08$) \dagger$ & 0.19 \\
\hline$\geq 2$ falls & $21(14)$ & $33(22)$ & $0.63(0.38$ to 1.04$) \dagger$ & 0.07 \\
\hline
\end{tabular}

*Incidence rate ratio.

tRelative risk.

the floor when barefoot and maximum balance range test wearing shoes). Six of the eight secondary outcome measures remained significantly different between the groups at the $\mathrm{P}<0.05$ level after Hochberg adjustment.

\section{DISCUSSION}

A multifaceted podiatry intervention was effective in reducing falls in community dwelling older people with disabling foot pain, suggesting that this approach may be a useful addition to existing falls prevention programmes. This randomised trial is the first to evaluate a falls prevention intervention specifically targeting foot and footwear risk factors. The observed 36\% reduction in falls rate is similar to the reduction achieved with individually prescribed multiple component home based exercises, Tai Chi, and cataract surgery reported in the most recent Cochrane review of community based falls prevention trials. ${ }^{38}$ In addition to the reduced falling rate, fewer participants in the intervention group than control group had a fracture resulting from a fall during the trial, but this did not reach significance $(\mathrm{P}=0.07)$. This pattern is similar to that found in other fall prevention studies involving home based exercise ${ }^{39}$ and cataract surgery. ${ }^{40}$ It is likely that the lack of a significant reduction in fractures in this trial resulted from the relatively small number of fractures reported, with consequent low statistical power for this outcome measure.

The proportion of fallers or multiple fallers did not differ significantly between the groups, although the trend was for a greater proportion of fallers in the control group, particularly multiple fallers. Although it is not uncommon for trials on falls to report a reduction in the rate of falls but no significant difference in the proportion of fallers, ${ }^{41-43}$ this trial may have been underpowered for detecting a difference in the proportion of fallers, as our sample had a lower risk of falls than anticipated. The a priori sample size calculation used a falls rate of $60 \%$ in the control group based on a previous study of older people with foot pain, but during the trial only $49 \%$ of the control group fell.

Analysis of the secondary outcome measures suggests that the observed reduction in falls may in part be mediated by increases in foot and ankle strength and range of motion, leading to improvements in balance and functional ability. It has been shown previously that muscle strength at the ankle is correlated with balance, ${ }^{445}$ walking speed, ${ }^{46}$ and functional movements. ${ }^{47-49}$ Although increases in muscle strength after exercise interventions with associated improvements in balance, functional ability, and reduction in falls have been well established, ${ }^{385051}$ previous studies have concentrated on muscle groups proximal to the foot and ankle. While this is the first large randomised trial to focus specifically on the foot and ankle, it concurs with smaller trials that have reported improvements in foot and ankle strength after exercise programmes. ${ }^{45253}$ The observed improvements in the intervention group in strength and range of motion, in conjunction with improvement in some balance measures, suggest that the intervention resulted in changes in the musculoskeletal system that reduces the risk of falling.

The multifaceted nature of the intervention makes it difficult to delineate the relative contribution of each component in preventing falls. However, it is likely that the exercise programme was the key component of the intervention, for two main reasons. Firstly, improvements occurred in the secondary outcomes of foot and ankle strength and range of motion, which are unlikely to have resulted from the footwear or foot orthoses components. Secondly, less than one third of the study population presented with inappropriate footwear, and only $17 \%(n=26)$ of the intervention group purchased new footwear, so the contribution of this component of the intervention would have been relatively minor. Although the foot orthoses used in the study were not specifically designed to improve balance, they may have had a direct effect on balance by improving foot stability and enhancing plantar sensory feedback ${ }^{54}$ and an indirect effect by reducing plantar pressure and foot pain, both of which have been identified as risk factors for falls..$^{55}$

The relatively low need to provide new footwear was a surprising aspect of this trial, as previous studies have indicated that between $43 \%$ and $75 \%$ of older people wear inappropriate footwear. ${ }^{12}{ }^{1356}$ A likely explanation for the relatively low prevalence of inappropriate footwear is that most of the participants regularly accessed podiatry services, where appropriate footwear would have been frequently emphasised. However, it also needs to be acknowledged that we did not consider participants' indoor footwear. It has previously been reported that selection of indoor footwear by older people is influenced primarily by comfort and low cost, and that household shoes are infrequently replaced. ${ }^{57}$ As such, it is possible that several participants wore suboptimal indoor footwear that may have contributed to their risk of falling.

\section{Adherence to the intervention}

Adherence to the intervention was generally good, with more than half of the participants performing $75 \%$ of the exercise sessions and wearing the foot orthoses on a regular basis. However, $29 \%$ of those identified as wearing inappropriate outdoor footwear did not take up the option of purchasing new shoes, despite receiving advice about the possible risks associated with their footwear and being provided with a voucher to partly cover the costs. Several previous studies have reported difficulties in convincing older 
Table 3| Secondary outcome measures at baseline and six month follow-up. Values are means (standard deviations) unless otherwise stated

\begin{tabular}{|c|c|c|c|c|c|c|}
\hline \multirow[b]{2}{*}{ Variables } & \multicolumn{2}{|c|}{ Podiatry intervention group $(n=153)$} & \multicolumn{2}{|c|}{ Control group $(n=152)$} & \multirow{2}{*}{$\begin{array}{l}\text { Adjusted mean difference } \\
\qquad(95 \% \mathrm{Cl}) \dagger\end{array}$} & \multirow[b]{2}{*}{$P$ value } \\
\hline & Baseline & Follow-up & Baseline & Follow-up & & \\
\hline \multicolumn{7}{|l|}{ Strength (Newtons): } \\
\hline Ankle dorsiflexion & $154.72(41.65)$ & $171.19(44.77)$ & $152.11(46.11)$ & $161.91(44.45)$ & $7.60(-0.41$ to 15.62$)$ & 0.063 \\
\hline Ankle plantarflexion & $206.17(55.29)$ & $228.94(51.86)$ & $199.01(51.72)$ & $220.86(51.10)$ & $3.94(-5.75$ to 13.63$)$ & 0.423 \\
\hline Ankle inversion & $100.73(34.91)$ & $106.14(34.58)$ & $102.90(34.66)$ & $102.61(31.56)$ & $5.33(0.53$ to 10.13$)$ & 0.030 \\
\hline Ankle eversion & $97.85(29.08)$ & $107.76(28.53)$ & $99.18(30.60)$ & $101.10(28.26)$ & $7.69(2.87$ to 12.51$)$ & $0.002^{*}$ \\
\hline Lesser toe plantarflexion & $68.00(25.06)$ & $74.11(30.04)$ & $67.95(27.18)$ & $70.13(27.11)$ & $4.01(-1.14$ to 9.17$)$ & 0.125 \\
\hline Hallux plantarflexion & $68.23(26.97)$ & $69.69(30.15)$ & $68.95(27.98)$ & $69.86(28.16)$ & $0.43(-4.00$ to 4.87$)$ & 0.847 \\
\hline \multicolumn{7}{|l|}{ Range of motion (degrees): } \\
\hline Ankle dorsiflexion, knee extended & $30.91(5.60)$ & $32.81(6.75)$ & $30.41(6.32)$ & $31.09(5.95)$ & $1.37(0.34$ to 2.41$)$ & $0.009^{*}$ \\
\hline Ankle dorsiflexion, knee flexed & $39.96(7.07)$ & $40.73(7.50)$ & $38.69(6.81)$ & $38.63(6.10)$ & 1.05 (0.18 to 1.92$)$ & $0.018^{*}$ \\
\hline Ankle inversion/eversion & $32.56(9.51)$ & $36.17(11.23)$ & $32.63(9.65)$ & $33.54(9.62)$ & $2.66(0.65$ to 4.66$)$ & $0.010^{*}$ \\
\hline 1st MTPJ dorsiflexion & $72.85(18.76)$ & $76.21(18.44)$ & $75.83(16.71)$ & $78.99(15.54)$ & $-0.18(-2.27$ to 1.91$)$ & 0.865 \\
\hline \multicolumn{7}{|l|}{ Balance tests: } \\
\hline Postural sway on floor, barefoot $\left(\mathrm{mm}^{2}\right)$ & $137.82(205.87)$ & $93.16(39.82)$ & $114.37(121.06)$ & $119.07(126.34)$ & $-28.63(-49.08$ to -8.17$)$ & $0.003^{*}$ \\
\hline Postural sway on foam, barefoot $\left(\mathrm{mm}^{2}\right)$ & $215.87(203.26)$ & $160.84(104.26)$ & $238.03(235.39)$ & $220.48(323.97)$ & $-51.02(-103.49$ to 1.44$)$ & 0.083 \\
\hline Postural sway on floor, shod $\left(\mathrm{mm}^{2}\right)$ & $114.66(75.67)$ & $103.59(41.00)$ & $120.62(76.03)$ & $117.73(119.62)$ & $-10.95(-29.76$ to 7.87$)$ & 0.478 \\
\hline Postural sway on foam, shod (mm²) & $201.49(148.90)$ & $179.10(118.58)$ & $224.15(182.76)$ & $190.93(194.90)$ & $-2.96(-34.42$ to 31.50$)$ & 0.888 \\
\hline Maximum balance range, barefoot $(\mathrm{mm})$ & $116.16(33.17)$ & $133.10(31.29)$ & $108.37(28.41)$ & $123.86(26.65)$ & $4.00(-1.21$ to 9.20$)$ & 0.131 \\
\hline Maximum balance range, shod (mm) & $125.02(27.74)$ & $140.44(28.12)$ & $122.48(27.18)$ & $127.80(29.10)$ & $10.83(5.48$ to 16.19$)$ & $<0.001^{*}$ \\
\hline Coordinated stability, barefoot (errors) & $9.20(8.13)$ & $8.07(7.71)$ & $10.18(8.40)$ & $9.23(7.83)$ & $-0.50(-1.74$ to 0.74$)$ & 0.051 \\
\hline Coordinated stability, shod (errors) & $7.78(7.17)$ & $7.15(6.67)$ & $8.96(7.80)$ & $7.39(6.65)$ & $0.48(-0.58$ to 1.54$)$ & 0.421 \\
\hline Lateral stability, barefoot $(\mathrm{mm})$ & $58.42(40.79)$ & $52.49(38.94)$ & $63.64(44.91)$ & $53.56(40.38)$ & $1.54(-6.71$ to 9.80$)$ & 0.889 \\
\hline Lateral stability, shod (mm) & $50.09(37.27)$ & $49.13(32.16)$ & $48.78(32.83)$ & $48.43(29.82)$ & $-0.52(-6.07$ to 7.11$)$ & 0.918 \\
\hline \multicolumn{7}{|l|}{ Functional ability: } \\
\hline Alternate step test (s) & $11.95(4.39)$ & $10.25(3.93)$ & $11.56(3.84)$ & $10.53(3.93)$ & $-0.53(-1.12$ to 0.07$)$ & 0.038 \\
\hline Six metre walk $(\mathrm{m} / \mathrm{s})$ & $0.95(0.20)$ & $0.98(0.20)$ & $0.96(0.20)$ & $0.99(0.21)$ & $0.00(-0.03$ to 0.03$)$ & 0.959 \\
\hline Sit to stand (s) & $13.41(4.16)$ & $12.72(6.64)$ & $13.37(4.56)$ & $12.43(5.79)$ & $0.29(-0.79$ to 1.38$)$ & 0.348 \\
\hline \multicolumn{7}{|l|}{ Falls risk: } \\
\hline PPA total score & $1.28(0.93)$ & $0.81(0.92)$ & $1.38(1.00)$ & $1.05(0.98)$ & $-0.17(-0.35$ to 0.01$)$ & 0.059 \\
\hline \multicolumn{7}{|l|}{ Foot pain and disability: } \\
\hline MFPDI, pain subscale & $3.86(1.95)$ & $2.75(2.11)$ & $4.03(2.04)$ & $3.26(2.52)$ & $-0.42(-0.91$ to 0.08$)$ & 0.101 \\
\hline MFPDI, function subscale & $8.01(4.39)$ & $5.65(4.59)$ & $8.04(4.40)$ & $6.24(4.85)$ & $-0.55(-1.49$ to 0.40$)$ & 0.257 \\
\hline \multicolumn{7}{|l|}{ Fear of falling: } \\
\hline Falls efficacy scale international & $13.08(3.99)$ & $11.94(4.28)$ & $13.38(4.51)$ & $12.49(3.97)$ & $-0.31(-1.06$ to 0.44$)$ & 0.419 \\
\hline \multicolumn{7}{|l|}{ Health related quality of life: } \\
\hline SF-12 physical score & $38.77(10.08)$ & $40.06(10.06)$ & $39.83(9.28)$ & $39.51(10.72)$ & $1.33(-0.40$ to 3.06$)$ & 0.131 \\
\hline SF-12 mental score & $50.16(11.14)$ & $50.61(10.32)$ & $49.09(10.44)$ & $50.12(9.55)$ & $-0.14(-2.00$ to 1.71$)$ & 0.881 \\
\hline
\end{tabular}

PPA=physiological profile assessment; MTPJ=metatarsophalangeal joint; MFPDI=Manchester foot pain and disability index, SF-12=short form 12 health survey.

${ }^{*} \mathrm{P}<0.05$ after retrospective testing using Hochberg procedure.

†Adjusted for baseline score and intervention group using analysis of covariance.

people to change their footwear to improve their foot health or decrease their risk of falls, ${ }^{58-60}$ which has been attributed to the unique role of footwear as both an item of clothing and a health related intervention. ${ }^{61}$ Given the somewhat conflicting requirements of aesthetics and function, specifically in relation to women's shoes, it is likely that full adherence to footwear interventions will continue to be difficult to achieve.

Despite the inherent difficulties in promoting adherence to footwear recommendations, the multifaceted intervention evaluated in this study could potentially be incorporated into routine podiatry practice or multidisciplinary falls prevention clinics. The home based exercise programme is feasible for older people to undertake, requires simple and inexpensive equipment, and can be easily explained to participants with the assistance of a booklet and accompanying DVD. Furthermore, the foot orthoses used are prefabricated, so do not require the time consuming and costly casting and manufacturing processes associated with individually customised devices. The cost effectiveness of the multifaceted intervention is yet to be undertaken, however, and would vary according to the clinical context in which it was to be administered.

\section{Strengths and limitations of the study}

The strengths of our study are its high completion rate and small losses to follow-up. However, the findings 


\section{WHAT IS ALREADY KNOWN ON THIS TOPIC}

Foot problems impair balance and gait and increase the risk of falls

Inappropriate footwear impairs balance and increases the risk of falls

\section{WHAT THIS STUDY ADDS}

A multifaceted podiatry intervention consisting of a foot and ankle exercise programme, foot orthoses, advice on footwear, subsidised footwear, and general falls education significantly reduced the rate of falls in community dwelling older people with disabling foot pain

need to be interpreted in the context of certain limitations. Firstly, owing to the nature of the intervention, it was not possible to blind participants to their group allocation. Secondly, the sample may have been biased towards volunteers with a heightened interest and commitment in the intervention, as 195 people who initially expressed interest declined participation, primarily due to reluctance to commit to the study for a 12 month period. Thirdly, the intervention did not target all relevant risk factors for foot and ankle. Both hallux valgus and deformity of the lesser toes have been shown to increase the risk of falls, ${ }^{9}{ }^{10}$ but these conditions generally require surgical treatment, which was beyond the scope of the study. Finally, care needs to be taken in generalising these findings, as all participants were living independently in the community, had disabling foot pain and an increased risk of falling, and regularly accessed podiatry services. Whether the intervention is effective in residential care settings or in older people without foot pain requires further investigation.

\section{Conclusions}

The findings of this study show that a multifaceted podiatry intervention is an effective falls prevention strategy in older people with disabling foot pain and an increased risk of falls. The reduction in falls is likely to be related to the significant improvements found in several measures of foot and ankle strength and range of motion, balance, and functional ability. The components of the intervention are inexpensive and relatively simple to implement, suggesting that the programme could be incorporated into routine podiatry practice or multidisciplinary falls prevention clinics.

We thank C Baycroft (Foot Science International) and M Dannals (Briggate Medical) for the supply of orthoses and other materials used in the project, and L Shaw and B Chapman (La Trobe University Health Sciences (linic) for their assistance and cooperation.

Contributors: HBM and SRL conceived the study. MJS and HBM were involved in the study design, study coordination, and data analysis and interpretation. SRL, KDH, and KBL were involved in the study design and data interpretation. MRF and EW were responsible for participant recruitment, database management, and administration of questionnaires and physical tests. All authors were involved in preparation of the manuscript. MJS and HBM are the guarantors. Funding: This study was funded by the National Health and Medical Research Council of Australia and the La Trobe University central large grant scheme. HBM is currently a National Health and Medical Research Council fellow (clinical career development award, 433049). The foot orthoses in this study were provided by Foot Science International, Christchurch, New Zealand.

Competing interests: All authors have completed the ICMJE uniform disclosure form at www.icmje.org/coi_disclosure.pdf (available on request from the corresponding author) and declare all authors received financial support from the National Health and Medical Research Council for the submitted work; no authors had financial relationships with any organisations that might have an interest in the submitted work in the previous three years; no other relationships or activities that could appear to have influenced the submitted work.

Ethical approval: This study was approved by the human ethics committee of La Trobe University.

Data sharing: The dataset is available from the corresponding author at h.menz@latrobe.edu.au.

1 Tinetti ME, Speechley M, Ginter SF. Risk factors for falls among elderly persons living in the community. $N$ Engl J Med 1988;319:1701-7.

2 Lord SR, Ward JA, Williams P, Anstey KJ. An epidemiological study of falls in older community-dwelling women: the Randwick falls and fractures study. Aust J Public Health 1993;17:240-54.

3 Lord SR, Menz HB, Tiedemann A. A physiological profile approach to falls risk assessment and prevention. Phys Ther 2003;83:237-52.

4 Rubenstein LZ, Josephson KR. The epidemiology of falls and syncope. Clin Geriatr Med 2002;18:141-58.

5 Dunn JE, Link CL, Felson DT, Crincoli MG, Keysor JJ, McKinlay JB. Prevalence of foot and ankle conditions in a multiethnic community sample of older adults. Am J Epidemiol 2004;159:491-8.

6 Hill C, Gill T, Menz H, Taylor A. Prevalence and correlates of foot pain in a population-based study: the North West Adelaide Health Study.J Foot Ankle Res 2008;1:2.

7 Menz HB, Tiedemann A, Kwan MM, Plumb K, Lord S. Foot pain in community-dwelling older people: an evaluation of the Mancheste Foot Pain and Disability Index. Rheumatology 2006;45:863-7.

8 Menz HB, Jordan KP, Roddy E, Croft PR. Characteristics of primary care consultations for musculoskeletal foot and ankle problems in the UK. Rheumatology 2010;49:1391-8.

9 Menz HB, Morris ME, Lord SR. Foot and ankle risk factors for falls in older people: a prospective study. I Gerontol A Biol Sci Med Sci 2006;61:866-70.

10 Mickle KJ, Munro BJ, Lord SR, Menz HB, Steele JR. ISB Clinical Biomechanics Award 2009: toe weakness and deformity increase the risk of falls in older people. Clin Biomech 2009;24:787-91.

11 Koepsell TD, Wolf ME, Buchner DM, Kukull WA, LaCroix AZ, Tencer AF, et al. Footwear style and risk of falls in older adults. J Am Geriatr Soc 2004;52:1495-501.

12 Larsen ER, Mosekilde L, Foldspang A. Correlates of falling during $24 \mathrm{~h}$ among elderly Danish community residents. Prev Med 2004;39:389-98.

13 Menz HB, Morris ME, Lord SR. Footwear characteristics and risk of indoor and outdoor falls in older people. Gerontology 2006;52:174-80.

14 Tencer AF, Koepsell TD, Wolf ME, Frankenfeld CL, Buchner DM, Kukull WA, et al. Biomechanical properties of shoes and risk of falls in older adults. J Am Geriatr Soc 2004;52:1840-6.

15 Australian Commission on Safety and Quality in Health Care Preventing falls and harm from falls in older people: best practice guidelines for Australian community care 2009. Australian Commission on Safety and Quality in Health Care, 2009.

16 Commonwealth of Australia. Don't fall for it. Falls can be prevented!A guide to preventing falls for older people. Commonwealth of Australia, 2007.

17 Help the Aged. Staying steady. Help the Aged, 2007.

18 Panel on Prevention of Falls in Older Persons, American Geriatrics Society and British Geriatrics Society. Summary of the updated American Geriatrics Society/British Geriatrics Society clinical practice guideline for prevention of falls in older persons. J Am Geriatr Soc 2011; 59:148-57.

19 Davison J, Bond J, Dawson P, Steen IN, Kenny RA. Patients with recurrent falls attending accident $\&$ emergency benefit from multifactorial intervention-a randomised controlled trial. Age Ageing 2005;34:162-8.

20 Lightbody E, Watkins C, Leathley M, Sharma A, Lye M. Evaluation of a nurse-led falls prevention programme versus usual care: a randomized controlled trial. Age Ageing 2002;31:203-10.

21 Mahoney JE, Shea TA, Przybelski R, Jaros L, Gangnon R, Cech S, et al. Kenosha County Falls Prevention Study: a randomized, controlled trial of an intermediate-intensity, community-based multifactorial falls intervention. J Am Geriatr Soc 2007;55:489-98.

22 McKiernan FE. A simple gait-stabilizing device reduces outdoor falls and nonserious injurious falls in fall-prone older people during the winter. J Am Geriatr Soc 2005;53:943-7.

23 Pfeiffer E. A short portable mental status questionnaire for the assessment of organic brain deficit in elderly patients. J Am Geriatr Soc 1975;23:433-41. 
24 Garrow AP, Silman AJ, Macfarlane GJ. The Cheshire foot pain and disability survey: a population survey assessing prevalence and associations. Pain 2004;110:378-84.

25 Tiedemann A, Shimada H, Sherrington C, Murray S, Lord S. The comparative ability of eight functional mobility tests for predicting falls in community-dwelling older people. Age Ageing 2008;37:430-5.

26 Spink MJ, Menz HB, Lord SR. Efficacy of a multifaceted podiatry intervention to improve balance and prevent falls in older people: study protocol for a randomised trial. BMC Geriatr 2008;8:30.

27 Menz HB, Sherrington C. The footwear assessment form: a reliable clinical tool to assess footwear characteristics of relevance to postural stability in older adults. Clin Rehabil 2000;14:657-64.

28 Lamb SE, Jorstad-Stein EC, Hauer K, Becker C. Development of a common outcome data set for fall injury prevention trials: the Prevention of Falls Network Europe consensus. J Am Geriatr Soc 2005;53:1618-22.

29 Garrow AP, Papageorgiou AC, Silman AJ, Thomas E, Jayson MIV, Macfarlane GJ. Development and validation of a questionnaire to assess disabling foot pain. Pain 2000;85:107-13.

30 Kempen GIJM, Yardley L, Van Haastregt JCM, Zijlstra GAR, Beyer N, Hauer K, et al. The short FES-I: a shortened version of the falls efficacy scale-international to assess fear of falling. Age Ageing 2008;37:45-50.

31 Ware J, Kosinski M, Keller S. A 12-item short-form health survey: construction of scales and preliminary tests of reliability and validity. Med Care 1996;34:220-33.

32 Robertson MC, Campbell AJ, Herbison P. Statistical analysis of efficacy in falls prevention trials. J Gerontol A Biol Sci Med Sci 2005;60A:530-4.

33 Twisk J, Proper K. Evaluation of the results of a randomized controlled trial: how to define changes between baseline and follow-up. J Clin Epidemiol 2004;57:223-8.

34 Rubin DB. Multiple imputation for nonresponse in surveys. Wiley, 1987.

35 Sterne JAC, White IR, Carlin JB, Spratt M, Royston P, Kenward MG, et al. Multiple imputation for missing data in epidemiological and clinical research: potential and pitfalls. BMJ 2009;338:b2393.

36 Hochberg Y. A sharper Bonferroni procedure for multiple tests of significance. Biometrika 1988;75:800-2.

37 Schulz KF, Grimes DA. Sample size slippages in randomised trials: exclusions and the lost and wayward. Lancet 2002;359:781-5.

38 Gillespie LD, Robertson MC, Gillespie WJ, Lamb SE, Gates S, Cumming RG, et al. Interventions for preventing falls in older people living in the community. Cochrane Database Syst Rev 2009;2:CD007146.

39 Robertson MC, Devlin N, Gardner MM, Campbell AJ. Effectiveness and economic evaluation of a nurse delivered home exercise programme to prevent falls. 1: Randomised controlled trial. $B M$ 2001;322:697-701.

40 Harwood RH, Foss AJE, Osborn F, Gregson RM, Zaman A, Masud T. Falls and health status in elderly women following first eye cataract surgery: a randomised controlled trial. Br J Ophthalmol 2005;89:53-9.

41 Cumming RG, Sherrington C, Lord SR, Simpson JM, Vogler C, Cameron ID, et al. Cluster randomised trial of a targeted multifactorial intervention to prevent falls among older people in hospital. BMJ 2008;336:758-60.

42 Haran MJ, Cameron ID, Ivers RQ, Simpson JM, Lee BB, Tanzer M, et al. Effect on falls of providing single lens distance vision glasses to multifocal glasses wearers: VISIBLE randomised controlled trial. BMJ 2010;340:c2265.
43 Shumway-Cook A, Silver IF, LeMier M, York S, Cummings $P$, Koepsell TD. Effectiveness of a community-based multifactorial intervention on falls and fall risk factors in community-living older adults: a randomized, controlled trial. J Gerontol A Biol Sci Med Sci 2007;62:1420-7.

44 Menz HB, Morris ME, Lord SR. Foot and ankle characteristics associated with impaired balance and functional ability in older people. J Gerontol A Biol Sci Med Sci 2005;60A:1546-52.

45 Vandervoort AA, Hayes KC. Plantarflexor muscle function in young and elderly women. Eur J Appl Physiol 1989;58:389-94.

46 Tiedemann A, Sherrington C, Lord SR. Physiological and psychological predictors of walking speed in older communitydwelling people. Gerontology 2005;51:390-5.

47 Bassey EJ, Bendall MJ, Pearson M. Muscle strength in the triceps surae and objectively measured customary walking activity in men and women over 65 years of age. Clin Sci 1988;74:85-9.

48 Hernandez ME, Goldberg A, Alexander NB. Decreased muscle strength relates to self-reported stooping, crouching, or kneeling difficulty in older adults. Phys Ther 2010;90:67-74.

49 Lord SR, Ward JA, Williams P, Strudwick M. The effect of a 12-month exercise trial on balance, strength, and falls in older women: $a$ randomized controlled trial. J Am Geriatr Soc 1995;43:1198-206.

50 Howe TE, Rochester L, Jackson A, Banks PM, Blair VA. Exercise for improving balance in older people. Cochrane Database Syst Rev 2007;4:CD004963.

51 Liu C-J, Latham NK. Progressive resistance strength training for improving physical function in older adults. Cochrane Database Syst Rev 2009;3:CD002759.

52 Hartmann A, Murer K, De Bie RA, De Bruin ED. The effect of a foot gymnastic exercise programme on gait performance in older adults: A randomised controlled trial. Disabil Rehabil 2009;31:2101-10.

53 Sohng KY, Moon JS, Song HH, Lee KS, Kim YS. Fall prevention exercise program for fall risk factor reduction of the community-dwelling elderly in Korea. Yonsei Med J 2003;44:883-91.

54 Hijmans JM, Geertzen JHB, Dijkstra PU, Postema K. A systematic review of the effects of shoes and other ankle or foot appliances on balance in older people and people with peripheral nervous system disorders. Gait Posture 2007;25:316-23.

55 Mickle KJ, Munro BJ, Lord SR, Menz HB, Steele JR. Foot pain, planta pressures, and falls in older people: a prospective study. J Am Geriatr Soc 2010;58:1936-40.

56 Sherrington C, Menz HB. An evaluation of footwear worn at the time of fall-related hip fracture. Age Ageing 2003;32:310-4.

57 Munro BJ, Steele JR. Household-shoe wearing and purchasing habits. A survey of people aged 65 years and older. J Am Podiatr Med Asso 1999;89:506-14.

58 Fortinsky R, lannuzzi-Sucich M, Baker D, Gottschalk M, King M, Brown $C$, et al. Fall-risk assessment and management in clinical practice: views from healthcare providers. J Am Geriatr Soc 2004;52:1522-6.

59 Knowles EA, Boulton AJ. Do people with diabetes wear their prescribed footwear? Diabet Med 1996;13:1064-8.

60 Williams AE, Rome K, Nester Cl. A clinical trial of specialist footwea for patients with rheumatoid arthritis. Rheumatology 2007; 46:302-7.

61 Williams AE, Nester CE, Ravey MJ, Kottink A, Morey-Klapsing G. Women's experiences of wearing therapeutic footwear in three European countries. J Foot Ankle Res 2010;3:23.

Accepted: 18 April 2011 